\title{
ANÁliSE do CRESCIMENTO DE RABANETE EM FUNÇÃo DE PERÍODOS DE CONVIVÊNCIA COM PLANTAS DANINHAS
}

\begin{abstract}
Valdere Martins dos Santos ${ }^{1}$, Luziano Lopes da Silva ${ }^{2}$, Patriccia da Cruz Ramos ${ }^{3}$, Susana Cristine Siebeneichler ${ }^{4}$, Dione Pereira Cardoso ${ }^{5}$, Daniele de Cássia Viera de Sousa ${ }^{6}$

RESUMO - O objetivo deste trabalho foi avaliar a influência de períodos de convivência com plantas daninhas no crescimento de plantas de rabanete. O delineamento experimental foi em blocos ao acaso, com seis tratamentos e quatro repetições. Foram avaliados 6 períodos de convivência com plantas daninhas, em cinco épocas $(0$, $5,10,15,21$ e 30 dias após a emergência). Foram determinadas a taxa de crescimento da cultura (TCC), taxa de crescimento relativo (TCR), taxa de assimilação líquida (TAL), taxa de crescimento absoluto (TCA), razão de área foliar (RAF) e área foliar específica (AFE). As TCC e TCR apresentaram rápido acúmulo de massa inicial, até o ponto máximo no $2^{\circ}$ intervalo de crescimento, posteriormente, houve declínio pela senescência da cultura. A TAL atingiu seu crescimento máximo no $3^{\circ}$ intervalo, verificando-se a seguir redução, com exceção dos tratamentos ( sem competição e sem competição a partir do $5^{\circ}$ dia) que apresentaram aumento durante todo o ciclo da cultura. Resposta semelhante foi observada também para TCA. Para RAF e AFE verificase que nos tratamentos com algum período de competição ocorreu incremento até os 17 DAE dias, seguida por redução mais acentuada até os 30 DAE. Conclui-se que as características morfofisiológicas de plantas de rabanete foram alteradas pela competição com plantas daninhas.
\end{abstract}

Palavras chave: área foliar, Raphanus sativus, taxa de crescimento.

\section{ANALYSIS OF THE GROWTH OF RADISH AS A FUNCTION OF PERIODS WITH WEED COMPETITION}

\begin{abstract}
The objective of this study was to evaluate the influence of coexistence periods with weeds in the growth of radish plants. The experimental design was randomized blocks, with six treatments and four replications. We evaluated six periods of coexistence (culture always kept in clean, with weed competition for 5, 10, 15, 21 and 30 days and with weed competition throughout the cycle of weeds with the crop of radish) in five seasons evaluation (5, 10, 15, 21 and 30 days after emergence). We determined the growth rate of the culture (TCC), relative growth rate (TCR), net assimilation rate (TAL), absolute growth rate (TCA), leaf area ratio (RAF) and specific leaf area (AFE). The TCC and TCR showed an initial phase with rapid mass accumulation until its peak in the second period of growth subsequently decline due to senescence of the culture period. The TAL reached its maximum growth in the third interval, verifying the following reduction, with the exception of treatments (without competition and without competition from the fifth day) which increased throughout the crop cycle. A similar response was also observed for TCA. For RAF and AFE, the treatments with some period of growth competition occurred up to 17 days DAE, followed by reduction to the more pronounced 30 days after emergence. The morphological and physiological characteristics are influenced by competition with weeds for growing radishes.
\end{abstract}

Keywords: growth rate, leaf area, Raphanus sativus.

\footnotetext{
${ }^{1}$ Autor para correspondência. Mestre em Produção Vegetal, Universidade Federal do Tocantins, Campus de Gurupi, valderemartins25@hotmail.com

${ }^{2}$ Doutorando em Produção Vegetal, Universidade Federal do Tocantins, Campus de Gurupi, lopes.agro@hotmail.com

${ }^{3}$ Engenheira Agrônoma, Secretaria da Agricultura, Pecuária e Desenvolvimento Agrário, patricciaramos@ hotmail.com

${ }^{4}$ Professora Associada, Universidade Federal do Tocantins, Campus de Gurupi, susana@ uft.edu.br

${ }^{5}$ Bolsista Prodoc-Capes, Universidade Federal do Tocantins, Campus de Gurupi, cardoso.dione@gmail.com

${ }^{6}$ Estudante de Agronomia, Universidade Federal de Tocantins, Campus de Gurupi.
} 


\section{INTRODUÇÃO}

O rabanete Raphanus sativus (L.), e uma olerícola da família das brassicáceas sendo essencialmente produzido em pequenas propriedades nos cinturões verdes das grandes metrópoles. Esta olerícola apresenta elevada rentabilidade, além do mais, a mesma apresenta ciclo relativamente curto proporcionando um maior e mais rápido giro de capital. Porém, no Brasil não é considerado uma cultura de expressão em termos de área e produção apesar de fazer parte da alimentação de vários pratos. Sua produção mundial é estimada em sete milhões de toneladas por ano, sendo o Japão um dos grandes produtores. (Linhares et al., 2015; Ito; Horie, 2008).

Entre os fatores que afetam a produção das plantas de rabanete, o período de convivência com plantas daninhas é de grande importância, devido às características de elevada taxa de crescimento, grande capacidade reprodutiva e elevada capacidade de exploração de nutrientes do solo, que lhes asseguram a sobrevivência em locais frequentemente perturbados. Além disso, requerem para seu desenvolvimento os mesmos fatores exigidos pela cultura, estabelecendo um processo competitivo quando em convivência conjunta (Ferreira et al., 2008; Cury et al., 2012).

A competição exercida pelas plantas daninhas constitui um dos fatores que mais limitam a produtividade da cultura, além da ocorrência de plantas daninhas promover o aumento do custo de produção, dificulta a colheita, deprecia a qualidade do produto e estas são hospedeiras de pragas e doenças (Pereira, 2004). A intensidade da competição normalmente é avaliada por meio de decréscimos de produção e/ou pela redução no crescimento da planta cultivada, como respostas à competição pelos recursos de crescimento disponíveis no ambiente - no caso, $\mathrm{CO}_{2}$, água, luz e nutrientes (Agostinetto et al., 2008; Freitas et al., 2009),porém sem considerar a análise de crescimento. Esta é um método que descreve as condições morfofisiológicas das plantas em intervalos de tempo e propõe acompanhar a dinâmica da produção fotossintética, mediante o acúmulo de massa seca (Povh \& Ono, 2008).

Diante do exposto, tornar-se necessário melhor compreender as alterações fisiológicas e índices biométricos das plantas de rabanete, na presença e na ausência de plantas daninhas. Portanto, objetivouse com este trabalho avaliar a influência dos períodos de convivência com plantas daninhas nas respostas morfofisiológicas de plantas de rabanete (Raphanus sativus $\mathrm{L}$.).

\section{MATERIAL E MÉTODOS}

O experimento foi conduzido em área experimental da Universidade Federal do Tocantins - Campus de Gurupi, localizado a $11^{\circ} 43^{\prime} 45^{\prime}$ 'S e $49^{\circ} 04^{\prime} 07^{\prime \prime} \mathrm{W}$, com altitude média de 287 metros. A temperatura média e precipitação pluviométrica acumulada são $25,5^{\circ} \mathrm{C}$ e $316,4 \mathrm{~mm}$, respectivamente, obtidos entre os meses de dezembro de 2009 e janeiro de 2010. O solo foi classificado como Latossolo Vermelho-Amarelo distrófico, cujas características químicas se encontram na Tabela 1.

Os valores de precipitações e as temperaturas ocorridas durante o período de condução do experimento são apresentados na Figura 1.

Foram levantados canteiros $0,8 \mathrm{~m}$ de largura x 10 $\mathrm{m}$ de comprimento $\mathrm{x} 0,1 \mathrm{~m}$ de altura. A adubação do solo foi realizada de acordo com a análise química e exigências da cultura, onde foi realizada uma adubação de plantio na dosagem de $150 \mathrm{~g} \mathrm{~m}^{\ell^{2}}$ de NPK 4-14-8.

Foram utilizadas sementes de rabanete (Raphanus sativus), cultivar Vip Crimson Seleção Especial. A semeadura foi realizada no dia 7 de dezembro de 2009, em espaçamento de $20 \mathrm{~cm}$ entre sulcos e o desbaste no dia 14 de dezembro de 2009, quando as plantas estavam com $5 \mathrm{~cm}$ de altura. A área foi irrigada por aspersão, uma vez por dia.

O experimento foi conduzido em delineamento de blocos casualizados, com quatro repetições. Os tratamentos foram constituídos por 6 períodos crescentes de convivência com plantas daninhas (CPD), considerados a partir do desbaste (Tabela 2), nos quais as plantas de rabanete permaneceram sob a interferência das plantas daninhas desde o plantio até os seguintes períodos (dias) do seu ciclo de desenvolvimento: 1$5 ; 1-10 ; 1-15 ; 1-21 ;$ cultura mantida sempre no limpo e convivência com plantas daninhas durante todo o ciclo da cultura. Após cada período, as plantas daninhas foram removidas das parcelas por meio de capinas manuais até a colheita.

Durante a condução do experimento, foram realizados todos os tratamentos fitossanitários necessários à cultura. 
Tabela 1 - Análise química do solo dos canteiros deste experimento

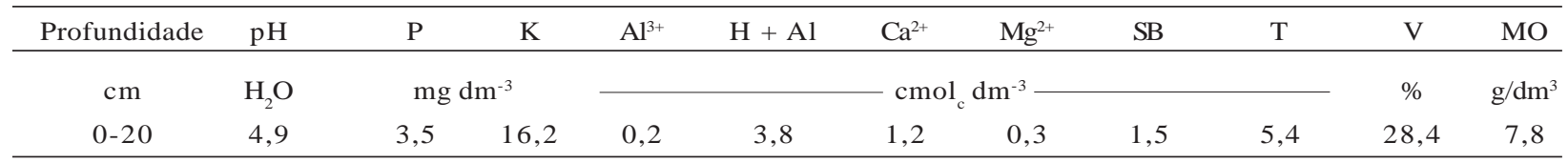

Atributos químicos da profundidade de $0-20 \mathrm{~cm} ; \mathrm{pH}$ em água - Relação 1:2,5; P e K - extrator Mehich 1; $\mathrm{Al}^{3+}, \mathrm{Ca}^{2+} \mathrm{e} \mathrm{Mg}^{2+}-\mathrm{Extrator}^{2}$ $\mathrm{KCl}\left(1 \mathrm{~mol} \mathrm{~L}^{-1}\right) ; \mathrm{H}+\mathrm{Al}$ - Extrator SMP; SB = Soma de Bases Trocáveis; $(\mathrm{T})=$ Capacidade de Troca Catiônica a pH 7,0; V - Índice de Saturação de Bases; e MO = matéria orgânica (oxidação: Na2Cr2O7 4N + H2SO4 10N.

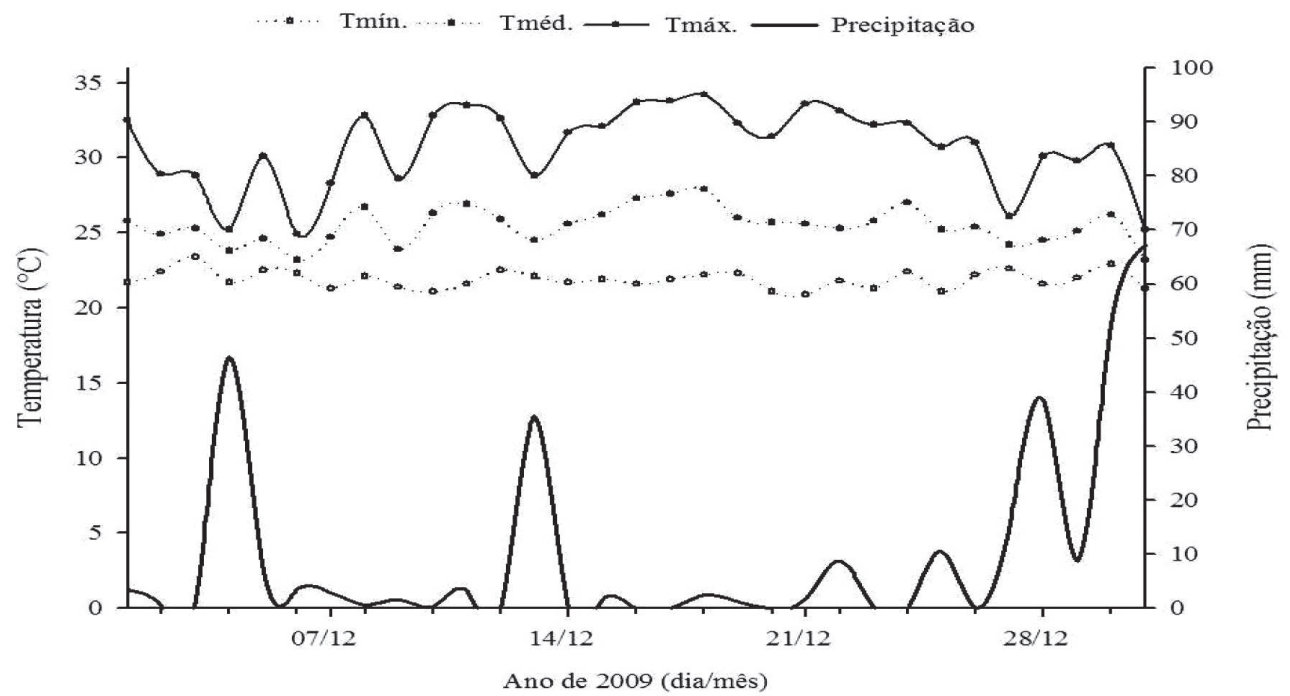

Figura 1 - Dados climáticos referentes ao mês de dezembro de 2009, obtidas na Estação Experimental de Pesquisa - EEP, situada no campus de Gurupi-TO.

Tabela 2 - Descrição dos tratamentos avaliados no experimento. Gurupi-TO, 2009

\begin{tabular}{ll}
\hline Tratamentos & \multicolumn{1}{c}{ Descrição } \\
\hline CPD 0 (Testemunha 1) $\stackrel{1}{ }$ & Cultura mantida sempre no limpo \\
CPD $\underline{3} 5$ & Convivência com plantas daninhas durante 5 dias após a emergência \\
CPD 10 & Convivência com plantas daninhas durante 10 dias após a emergência \\
CPD 15 & Convivência com plantas daninhas durante 15 dias após a emergência \\
CPD 21 & Convivência com plantas daninhas durante 21 dias após a emergência \\
CPD 30 DAP (Testemunha 2) $\stackrel{2}{ }{ }^{\prime}$ & Convivência com plantas daninhas durante todo o ciclo \\
\hline
\end{tabular}

$\stackrel{1}{ }$ Cultivo livre de planta daninha durante todo o ciclo; $\stackrel{2}{\prime}$ cultivo com plantas daninhas durante todo o ciclo; $\stackrel{3}{3}$ convivência com plantas daninhas; $\stackrel{4}{ }$ dias após o plantio.

O experimento foi avaliado em seis épocas de avaliações $(0,5,10,15,21$ e 30 dias após a emergência). Para a determinação das características foram coletadas três plantas por parcela, colhidas manualmente, e acondicionadas em sacos de papel. Em seguida, foram transportados ao laboratório, onde às plantas de rabanete, foram separadas em caule e folha.
Para estimar a área foliar a partir das relações entre a massa seca dos discos, área total dos discos e massa seca total das folhas foram retirados discos de lâmina foliar por meio de um furador cilíndrico com área interna conhecida. Posteriormente, todas as partes das plantas foram mantidas em estufa de circulação forçada, com temperatura de $70^{\circ} \mathrm{C}$ até obterem massa 
constante, quando foi determinada a massa da matéria seca. A massa da matéria seca total da parte aérea foi obtida pela soma das massas da matéria seca do caule e da folha.

Os dados de massa seca das partes das plantas possibilitaram a realização dos cálculos das seguintes variáveis: taxa de crescimento da cultura (TCC), que representa a capacidade de produção de fitomassa da cultura, ou seja, a quantidade total de massa seca acumulada por unidade de área do solo em função do tempo; taxa de crescimento relativo (TCR), que indica o incremento de massa seca (g) por unidade de massa seca ( $\mathrm{g}$ ) ao longo do tempo de avaliação (semanal); taxa de assimilação líquida (TAL), que expressa à taxa de fotossíntese líquida em termos de massa seca produzida, consistindo no aumento da massa seca $(\mathrm{g})$ em relação à área foliar $\left(\mathrm{cm}^{2}\right)$ no período avaliado (semanal); taxa de crescimento absoluto (TCA), que indica a velocidade de crescimento médio no determinado período de observação, consistindo no aumento da massa seca ( $\mathrm{g}$ ) em relação ao tempo de observação (semanal); razão de área foliar (RAF) que representa a área foliar útil para a fotossíntese; e área foliar específica (AFE), consistindo na área foliar $\left(\mathrm{cm}^{2}\right)$ em relação a sua massa seca (g) (Benincasa, 2003). Com avaliações: $1=$ intervalo entre 10 e $15 ; 2=$ entre 15 e $20 ; 3=$ entre 20 e $25 ; 4=$ entre 25 e 30 dias após a emergência

Para a análise dos dados, RAF e AFE, foram ajustados equações de regressão e seus respectivos coeficientes de determinação, ao nível de significância de 0,05. E para os demais parâmetros TAL, TCC, TCR e TCA não houve ajuste de equação regressão.

\section{RESULTADOS E DISCUSSÃO}

A taxa de assimilação líquida (TAL) aumentou em todos os tratamentos até atingir seu crescimento máximo no $3^{\circ}$ intervalo, verificando-se a seguir redução nos valores da TAL, com exceção dos tratamentos (sem competição e sem competição a partir do $5^{\circ}$ dia) que apresentaram aumento durante todo o ciclo da cultura (Figura 2).

O comportamento crescente nos valores de TAL nos primeiros intervalos ocorreu devido á menor área foliar existente, a elevada capacidade fotossintética das folhas e pela transformação dos fotoassimilados em massa seca de folha (Oliveira et al., 2005).

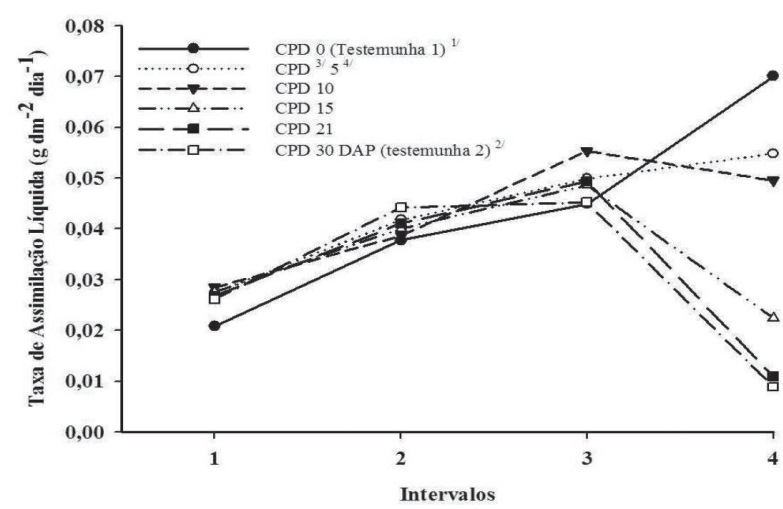

Figura 2 - A Taxa de Assimilação Líquida da cultura do rabanete (Raphanus sativus) cultivar Vip Crimson, em função dos intervalos $(1=$ intervalo entre 10 e $15 ; 2=$ entre 15 e $20 ; 3=$ entre 20 e $25 ; 4=$ entre 25 e 30 dias após a emergência). Desvio-padrão médio $=0,01 \mathrm{~g} \mathrm{dm}^{2} \mathrm{dia}^{-1}$.

Os decréscimos nos valores da TAL, nos tratamentos CPD 15, CPD 21 e CPD 30, ocorreram, provavelmente, em função da redução nos valores de massa seca destas plantas, em decorrência dos efeitos da competição excedida pelas plantas daninhas. Outro fator é que a taxa assimilatória líquida (TAL) é um índice de eficiência fotossintética da planta, que reflete a quantidade de massa seca assimilada por unidade de área foliar por dia (Hunt, 2003). Dessa forma, podese inferir que a competição com plantas daninhas, contribuiu para diminuir a TAL.

A taxa de crescimento da cultura (TCC) apresentou fase inicial com rápido acúmulo de massa seca em todos os tratamentos, até chegar ao seu ponto máximo, que ocorreu no $2^{\circ}$ intervalo de crescimento, posteriormente observa-se uma redução nos valores da TCC em todos os tratamentos durante o restante dos períodos de avaliação (Figura 3).

Normalmente, os valores da TCC, após um aumento inicial, chegam a seus valores máximos, decrescendo conforme a maturação das plantas devido à paralisação do crescimento vegetativo, perda de folhas e senescência (Zucareli et al., 2010). A TCC representa a capacidade de produção de fitomassa da cultura, ou seja, a quantidade total de massa seca acumulada por unidade de área em função do tempo (Benincasa, 2003).

Os valores encontrados para a taxa de crescimento da cultura no período de máxima produção variaram 


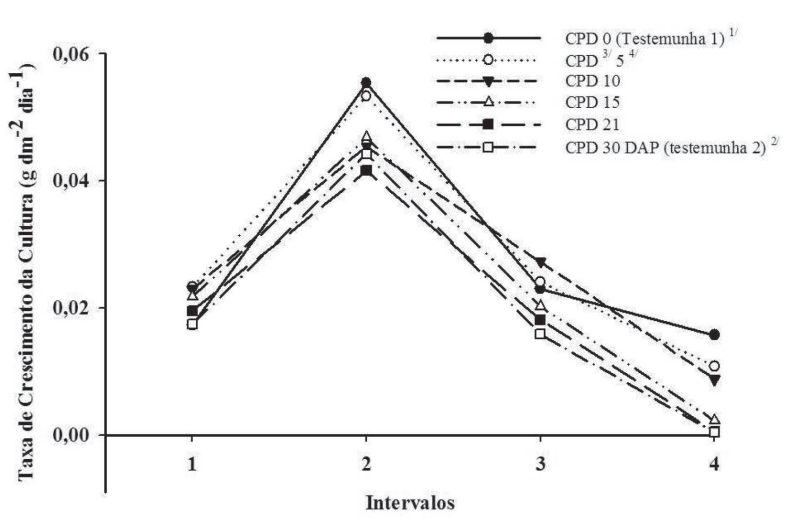

Figura 3 - ATaxa de Crescimento da Cultura do rabanete (Raphanus sativus) cultivar Vip Crimson, em função dos intervalos $(1=$ intervalo entre 10 e $15 ; 2=$ entre 15 e $20 ; 3$ $=$ entre 20 e $25 ; 4=$ entre 25 e 30 dias após a emergência). Desvio-padrão médio $=0,02 \mathrm{~g} \mathrm{dm}^{2} \mathrm{dia}^{-1}$.

a medida que se aumentou o período de competição da cultura do rabanete com as plantas daninhas, ou seja, a medida que aumentou o período de competição com as plantas daninhas houve redução da velocidade de crescimento inicial das plantas de rabanete. Portanto, as plantas de rabanete, sem competição, apresentaram um crescimento inicial mais rápido, permitindo que essas plantas conseguissem cobrir sua área de exploração disponível mais rapidamente, possibilitando assim, uma melhor e mais rápida exploração dos recursos naturais disponíveis no solo.

A taxa de crescimento relativo (TCR) apresentou o mesmo comportamento de crescimento que a TCC, em que as plantas de rabanete demonstraram uma fase inicial com rápido acúmulo de material, até atingir seu ponto máximo no $2^{\circ}$ intervalo de crescimento, com posterior queda em seus valores até o final do ciclo da cultura (Figura 4). Declínios nos valores da TCR geralmente são esperados, pois conforme a planta vai atingindo sua maturidade ocorre aumento da necessidade de fotoassimilados para manutenção das estruturas já formadas, o que diminui a quantidade de fotoassimilados disponíveis para o crescimento (Ferrari et al., 2008).

Esse rápido acúmulo de material seguido de um menor incremento pode ser explicado pelo aumento da competição intraespecífica pelos principais fatores ambientais responsáveis pelo crescimento (Benincasa, 2003). Isto também é observado em maracujazeiro-doce (Ferrari et al., 2008), tomate SM-16 (Lopes et al., 2011),

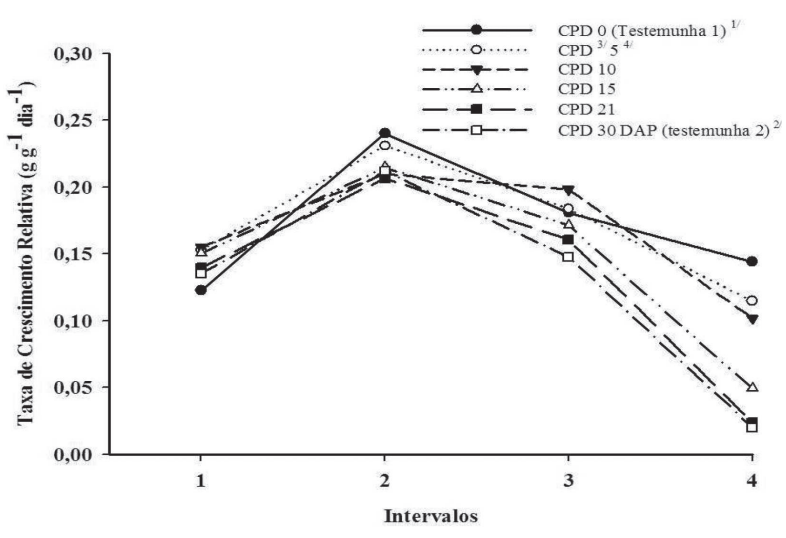

Figura 4 - A Taxa de Crescimento Relativo da cultura do rabanete (Raphanus sativus) cultivar Vip Crimson, em função dos intervalos $(1=$ intervalo entre 10 e $15 ; 2=$ entre 15 e $20 ; 3=$ entre 20 e $25 ; 4=$ entre 25 e 30 dias após a emergência). Desvio-padrão médio $=0,06 \mathrm{~g} \mathrm{~g}^{-1} \mathrm{dia}^{-1}$.

manjericão (Barreiro et al., 2006) e alface (Cancellier et al., 2010).

A taxa de crescimento relativo reflete o aumento da massa seca, num intervalo de tempo, sendo a medida mais apropriada para avaliação do crescimento vegetal (Benincasa, 2003). No último intervalo de avaliação percebe-se que na medida em que se aumentam os períodos de competição da cultura do rabanete com as plantas daninhas, diminuem os valores da taxa de crescimento relativo em função da diminuição da eficiência das plantas em produzir massa seca a partir do material pré-existente.

A taxa de crescimento absoluto (TCA) apresentou tendência de crescimento semelhante a TAL, nos tratamentos que passaram por um período maior de convivência com as plantas daninhas. Nos tratamentos (CPD 15, CPD 21 e CPD 30) verifica-se que a TCA aumentou até atingir seu crescimento máximo, no $3^{\circ}$ intervalo, sendo que em seguida houve uma redução nos valores da TCA até o $4^{\circ}$ e último intervalo, contudo, os tratamentos (CPD 0, CPD 5 e CPD 10) mantiveram seu crescimento até o último intervalo de avaliação (Figura 5).Segundo Fontes et al.(2005), valores diferentes na taxa de crescimento da cultura podem ser causados por diversos fatores entre os quais variedade, densidade de plantio, manejo, condições ambientais, entre outras.

No cultivo do pimentão é comum verificar que a TCA cresce durante todo o ciclo da cultura (Lopes 
et al., 2011). Resultados semelhantes foram encontrados por Silva et al. (2010), onde a TCA atingiu o máximo no final do período de avalia-ção, aos 126 DAT, na cultura do pimentão.

As plantas de rabanete que passaram por período de maior convivência com as plantas daninhas apresentaram uma TCA sempre inferior, atribuindose estas diferenças ao fato dessas plantas apresentarem menor área foliar (menor interceptação da radiação solar), menor teor de massa seca (menor eficiência fotossintética) e menor conteúdo de água (turgescência para crescimento) em relação ao tratamento sem competição. Segundo Benincasa (2003), a TCA pode ser usada para estimar a velocidade média de crescimento ao longo do período de observação, de forma que maiores períodos de convivência com plantas daninhas proporcionaram menores velocidades de crescimento em plantas de rabanete.

A razão de área foliar (RAF) declinou conforme o ciclo fenológico da cultura, com exceção do tratamento (CPD 0), demonstrando acréscimos de valores até aos 17 DAE e redução mais acentuada da RAF até os 30 DAE (Figura 6). Segundo Benincasa (2003), a RAF representa a área foliar útil para a fotossíntese, e quantifica o crescimento da área foliar em relação à planta, ou seja, através da RAF se detectam os efeitos da alocação de assimilados para as folhas e a proporção de assimilados entre área foliar e massa seca da planta.

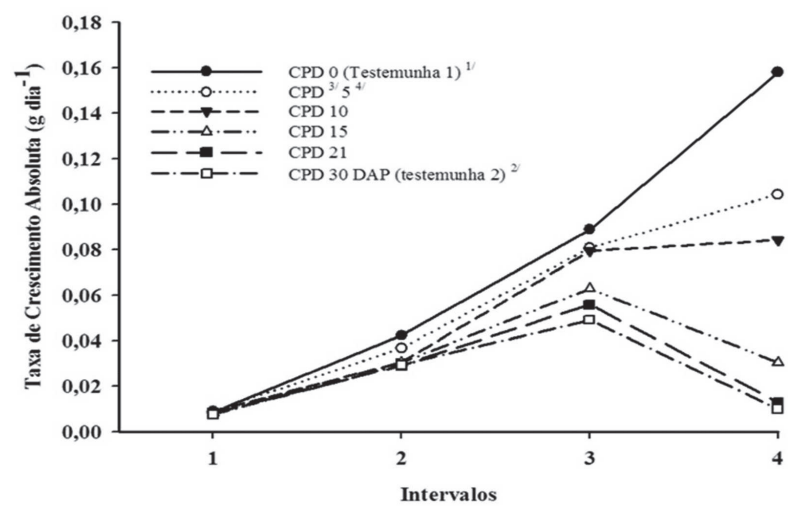

Figura 5 - A Taxa de Crescimento Absoluto da cultura do rabanete (Raphanus sativus) cultivar Vip Crimson, em função dos intervalos $(1=$ intervalo entre 10 e $15 ; 2=$ entre 15 e $20 ; 3=$ entre 20 e $25 ; 4=$ entre 25 e 30 dias após a emergência). Desvio-padrão médio $=0,04 \mathrm{~g} \mathrm{dia}^{-1}$.
A redução nos valores da RAF conforme o avanço do ciclo da cultura ocorre devido à redução na potencialidade de produção de folhas, a interferência das folhas superiores sobre as inferiores, a senescência e a queda das folhas, além do surgimento de estruturas e tecidos não-assimilátorios, como flores, vagens e sementes, que contribuem para o aumento da massa seca total (Benincasa, 2003; Zucareli et al., 2010).Segundo Silva et al. (2010) na cultura do pimentão reduções nos valores da RAF indica decréscimo na quantidade de assimilados destinados às folhas, o que, consequentemente, ocasionou redução na taxa de crescimento relativo.

Para a área foliar específica (AFE), observou-se comportamento semelhante aos ocorridos na RAF, em que foi verificado comportamento decrescente dos 10 aos 30 DAE, nos tratamentos em que ocorreram algum período de competição com plantas daninhas, e comportamento crescente até por volta dos $17 \mathrm{DAE}$ dias, seguida por redução mais acentuada nos valores da RAF até os 30 DAE no tratamento sem competição (CPD 0) (Figura 7).

Segundo Benincasa (2003), no início do desenvolvimento, os valores da AFE podem ser maiores, revelando folhas pouco espessas, com pouca massa seca e área foliar. Com o desenvolvimento das plantas, aumentam-se a área foliar e a massa seca de folhas, reduzindo os valores dessa variável. Isso ocorre em função do peso da folha ser um fator de divisão para a AFE, e, assim, inversamente proporcional a esta variável (Radin et al., 2004).

\section{CONCLUSÕES}

As características de crescimento da cultura do rabanete são afetadas negativamente pela competição com plantas daninhas.

À medida que aumentou o período de competição com as plantas daninhas houve redução da velocidade de crescimento inicial das plantas de rabanete, este contribuiu para diminuir a TAL, TCC, TCR e TCA.

É recomendável manter a cultura do rabanete livre de convivência com plantas daninhas a partir do $5^{\circ}$ dia após a emergência, para possibilitar maior crescimento das plantas. 


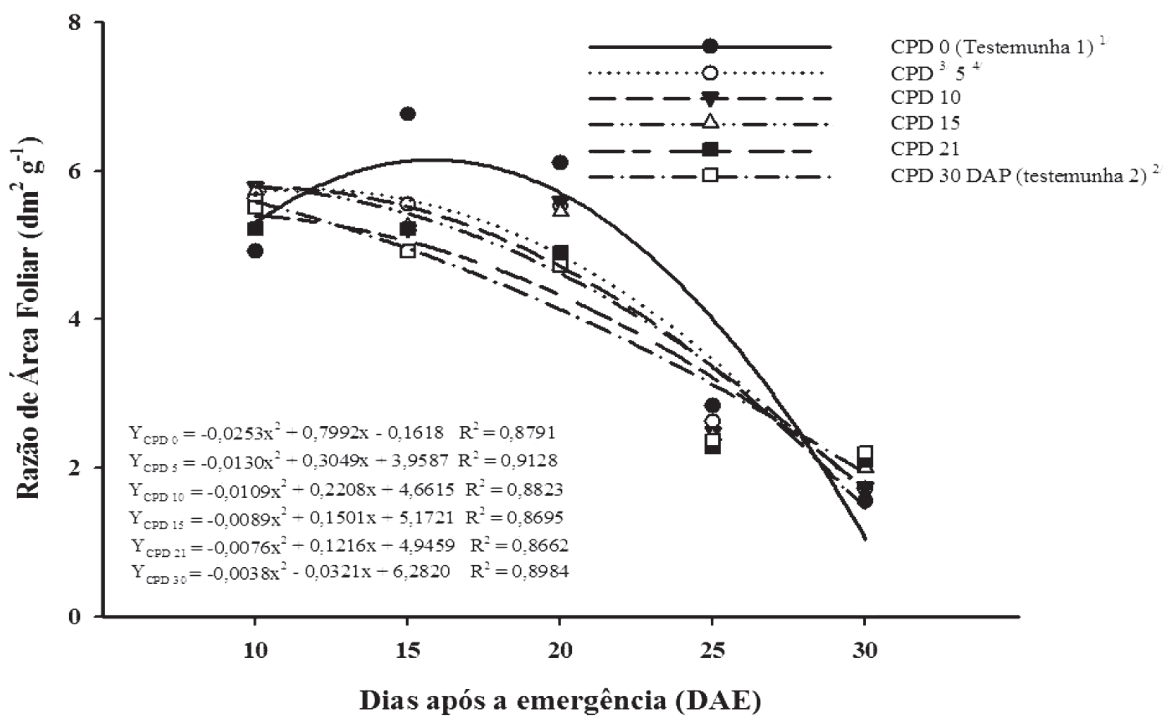

Figura 6 - A Razão de Área Foliar da cultura do rabanete (Raphanus sativus) cultivar Vip Crimson, em diferentes épocas de avaliações $(5,10,15,21$ e 30 dias após a emergência), ao nível de significância de 0,05. Desvio-padrão médio $=0,01 \mathrm{dm}^{2} \mathrm{~g}^{-1}$.

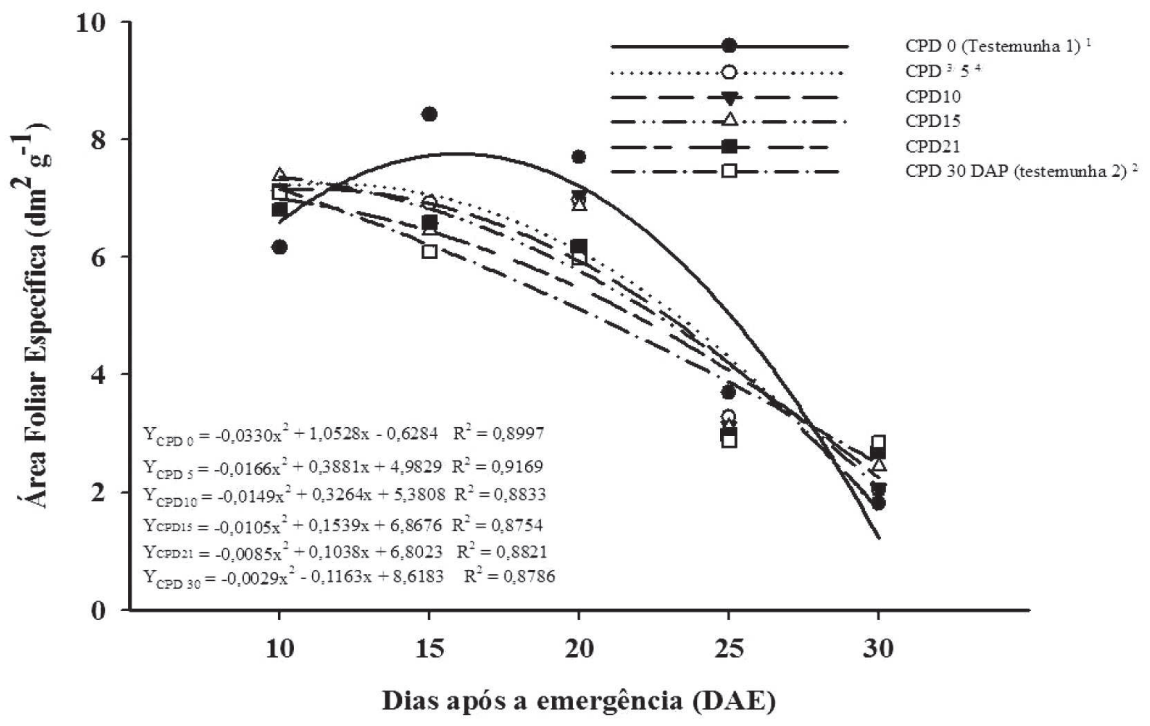

Figura 7 - A Área Foliar Específica da cultura do rabanete (Raphanus sativus) cultivar Vip Crimson, em diferentes épocas de avaliações $(5,10,15,21$ e 30 dias após a emergência), ao nível de significância de 0,05. Desvio-padrão médio $=2,32 \mathrm{dm}^{2} \mathrm{~g}^{-1}$.

\section{LITERATURA CITADA}

AGOSTINETTO, D.; RIGOLI, R.P.; SCHAEDLER, C.E. et al. Período crítico de competição de plantas daninhas com a cultura do trigo. Revista Planta Daninha, v.26, n.2, p.271-278, 2008.
BARREIRO, A.P.; ZUCARELI, V.; ONO, E.O. et al. Análise de crescimento de plantas de manjericão tratadas com reguladores vegetais. Revista Bragantia, v.65, n.4, p.563-567, 2006. 
BENINCASA, M.M.P. Análise de Crescimento de Plantas: noções básicas. FUNEP, Jaboticabal, 2003. 41p.

CANCELLIER, L.L.; ADORIAN, G.C.; RODRIGUES, H.V.M. et al. Doses de potássio nas respostas morfofisiológicas de alface. Revista

Caatinga, v.23, n.4, p.21-27, 2010.

CURY, J.P.; SANTOS, J.B.; SILVA, E.B. et al. Acúmulo e partição de nutrientes de cultivares de milho em competição com plantas daninhas.

Revista de Planta Daninha, v.30, n.2, p.287-296, 2012.

FERRARI, T.B.; FERREIRA, G.; ZUCARELI, V. et al. Efeito de reguladores vegetais nos índices da análise de crescimento de plântulas de maracujazeiro-doce (Passifloraalata Curtis).

Revista Biotemas, v.21, n.3, p.45-51, 2008.

FERREIRA, E.A.; CONCENÇO, G.; SILVA, A.A. et al. Potencial competitivo de biótipos de azevém (Lolium multiflorum). Planta Daninha, v.26, n.2, p.261-269, 2008.

FONTES, P.C.R.; DIAS, E.N.; SILVA, D.J.H. Dinâmica do crescimento, distribuição de matéria seca e produção de pimentão em ambiente protegido. Revista Horticultura

Brasileira, v.23, n.1, p.94-99, 2005.

FREITAS, F.C.L.; ALMEIDA, M.E.L.; NEGREIROS, M.Z. et al. Períodos de interferência de plantas daninhas na cultura da cenoura em função do espaçamento entre fileiras. Planta Daninha, v. 27, n.3, p.473-480, 2009.

HUNT, R. Growth analysis, individual plants. In: THOMAS, B. et al. (Ed.). Encyclopedia of applied plant sciences. London: Academic, p.579-588. 2003.

ITO, H.; HORIE, H.A. A chromatographic method for separating and identifying intact -Methylthio-3Butenyl Glucosinolate in Japanese Radish (Raphanus sativus L.). Japan Agricultural Research Quarterly, v.42, n.2, p.109-114, 2008.

LINHARES, P.C.F.; PEREIRA, M.F.S.; OLIVEIRA, B.S. et al. Produtividade de rabanete em sistema orgânico de produção. Revista Verde, v.5, n.5, p.94-101, 2010.
LINHARES, P.C.F.; OLIVEIRA, J.D.; ALMEIDA, A.M.B.; NEVES, A.P.M.; CUNHA, L.M.M.; COELHO, D.C.; SILVA, F.M. Eficiência econômica da aplicação do esterco bovino na cultura do rabanete. INTESA (Pombal - PB - Brasil), v.9, n.1, p.59-63, Jan-Jun, 2015.

LOPES, W.A.; NEGREIROS, M.Z.; DOMBROSKI, J.L.D. et al. Análise do crescimento de tomate 'SM-16' cultivado sob diferentes coberturas de solo. Revista Horticultura Brasileira, v.29, n.4, p.554-561, 2011.

OLIARI, I.C.R.; UMBURANAS, R.C.; ESCHEMBACK, V. et al. Efeito da restrição de luz solar e aumento da temperatura no crescimento de plantas de rabanete.

Revista Pesquisa Aplicada \& Agrotecnologia, v.3, n.3, p.85-96, 2010.

OLIVEIRA, F.R.A.; OLIVEIRA, F.A.; MEDEIROS, J.F. et al. Interação entre salinidade e fósforo na cultura do rabanete. Revista Ciência Agronômica, v.41, n.4, p.519-526, 2010.

OLIVEIRA, R.A.; DAROS, E.; ZAMBON, J.L.C. et al. Crescimento e desenvolvimento de três cultivares de cana-de-açúcar, em cana-planta, no estado do Paraná: taxas de crescimento. Revista Scientia Agraria, v.6, n.1-2, p.85-89, 2005.

PEREIRA, W. Manejo e controle de plantas daninhas em áreas de produção de sementes de hortaliças. In: IV Curso sobre tecnologia de produção de sementes de hortaliças. Brasília: SBH. Embrapa Hortaliças, p.1-20, 2004. Disponível em <http://www.cnph.embrapa.br/sistprod/cebola/ plantas_daninhas.htm>17 Set. 2012.

POVH, J.A.; ONO, E.O. Crescimento de plantas de Salvia officinalis sob ação de reguladores de crescimento vegetal. Revista Ciência Rural, v.38, n.8, p.2186-2190, 2008.

RADIN, B.; JUNIOR, C.R.; MATZENAUER, R. et al. Crescimento de cultivares de alface conduzidas em estufa e a campo. Revista Horticultura Brasileira, v.22, n.2, p.178-181, 2004.

SILVA, C.J.; COSTA, C.C.; DUDA, C.; TIMOSSI, P.C.; LEITE, I.C. Crescimento e produção de rabanete cultivado com diferentes doses de húmus de minhoca e esterco bovino. Revista Ceres, v.53, n.305, p.25-30, 2006. 
SILVA, P.I.B.; NEGREIROS, M.Z.; MOURA, K.K.C.F. et al. Crescimento de pimentão em diferentes arranjos espaciais. Revista Pesquisa Agropecuária Brasileira, v.45, n.2, p.132-139, 2010.
ZUCARELI, C.; RAMOS JUNIOR, E.U.; OLIVEIRA, M.A. et al. Índices biométricos e fisiológicos em feijoeiro sob diferentes doses de adubação fosfatada. Revista Semina: Ciências Agrárias, v.31, n.1, p.1313-1324, 2010.

Recebido para publicação em 01/05/2015 e aprovado em 30/07/2015. 